\section{Revisão sistemática de dietas de emagrecimento: papel dos componentes dietéticos}

\author{
Systematic review of weight loss diets: role of dietary components
}

Jussara C. de Almeida ${ }^{1,2}$, Ticiana C. Rodrigues',

Flávia Moraes Silva', Mirela J. de Azevedo'

\section{RESUMO}

O excesso de peso corporal é o sexto mais importante fator de risco para doenças crônicas não transmissíveis. Inúmeras publicações foram produzidas nos últimos anos para avaliar a melhor alternativa para perda de peso. 0 objetivo desta revisão sistemática foi analisar criticamente o papel dos componentes dietéticos (macronutrientes e/ou alimentos) nas dietas de emagrecimento para indivíduos adultos descritas recentemente na literatura. Foram selecionados ensaios clínicos randomizados com pelo menos um ano de acompanhamento publicados no MedLine (língua portuguesa, inglesa e espanhola) de 2004 a 2009. Dos 23 estudos com diferentes tipos de dietas, 13 apresentaram taxa de abandono $\geq 25 \%$ em pelo menos uma das dietas. Em conclusão, nos estudos em que a perda ponderal foi $>5 \%$ do peso inicial, essa perda foi associada à restrição de energia proveniente da dieta. Além disso, o seguimento de dieta com restrição de carboidratos ou mediterrânea poderia representar uma alternativa à restrição energética, devendo esses dados ainda ser confirmados. Arq Bras Endocrinol Metab. 2009;53(5):673-87.

Descritores

Perda de peso; dieta; obesidade; peso corporal; revisão sistemática

\begin{abstract}
Being overweight is the sixth most important risk factor for chronic non-transmissible diseases. Many publications have been produced in recent years to evaluate the best weight loss alternative. The aim of this systematic review was to critically assess the role of dietary components (macronutrients and/or foods) in weight loss diets in adults recently described in the literature. Randomized clinical trials, with at least one year of follow-up, were selected in MedLine (in Portuguese, English and Spanish languages) from 2004 to 2009. Among the 23 studies included with different types of diets, 13 presented a rate of withdrawal from the study $\geq 25 \%$ in at least one of the diets. In conclusion, most diets where the weight loss was $>5 \%$ of initial weight were energy restricted. Furthermore, following low carbohydrate or Mediterranean diets can be an alternative to isolated energy restriction, but these data are yet to be confirmed. Arq Bras Endocrinol Metab. 2009;53(5):673-87.
\end{abstract}

Keywords

Weight loss; diet; obesity; body weight; systematic review

\author{
Serviço de Endocrinologia do \\ Hospital de Clínicas de Porto \\ Alegre, Universidade Federal \\ do Rio Grande do Sul (UFRGS), \\ Porto Alegre, RS, Brasil \\ ${ }^{2}$ Curso de Nutrição, Departamento \\ de Medicina Social, Faculdade \\ de Medicina, UFRGS, Porto \\ Alegre, RS, Brasil
}

Correspondência para: Jussara C. de Almeida Serviço de Endocrinologia do Hospital de Clínicas de Porto Alegre Rua Ramiro Barcelos, 2350, Prédio 12, 4aar an 90035-003 - Porto Alegre, RS, Brasil jussara.carnevale@terra.com.br

Recebido em 27/Mar/2009 Aceito em 22/Jun/2009

\section{INTRODUÇÃO}

$\mathrm{O}$ excesso de peso corporal é o sexto fator de risco mais importante para doenças crônicas não transmissíveis em todo o mundo (1). A obesidade é definida como o acúmulo de gordura corporal, resultando em excesso de peso. A maneira mais frequentemente utilizada para quan- tificar a obesidade é por meio do índice de massa corporal (IMC). Indivíduos com IMC acima de $25 \mathrm{~kg} / \mathrm{m}^{2}$ são classificados como portadores de sobrepeso e com IMC maior ou igual a $30 \mathrm{~kg} / \mathrm{m}^{2}$ são considerados obesos (2).

Cerca de 1,1 bilhão de adultos e $10 \%$ das crianças têm, atualmente, sobrepeso ou obesidade (1). No Brasil, 
a prevalência de sobrepeso observada em pesquisa realizada pelo Instituto Brasileiro de Geografia e Estatística (2002-2003) foi de $41 \%$ para os homens e $39,2 \%$ para as mulheres (3). Mais recentemente, dados nacionais apresentaram uma prevalência de $43 \%$ de sobrepeso e $16 \%$ de obesidade em mulheres de 15 a 49 anos de idade (4). Essa prevalência pode ser diferente de acordo com a região do país. Em estudo transversal de base populacional realizado na região sul do Brasil, 23,5\% dos 2.002 adultos avaliados foram classificados como obesos (5). Dessa forma, o excesso de peso é um problema atual de saúde pública nas diversas populações, e a perda de peso tem sido uma preocupação comum na população em diferentes faixas etárias. Nesse cenário, é atraente a ideia de perda ponderal rápida sem a adoção da estratégia de redução da ingestão de energia proveniente da dieta e aumento do gasto energético a partir de prática regular de atividade física (6). Neste sentido, foi crescente o surgimento de dietas populares para combater a obesidade ao longo das últimas três décadas (7).

As dietas para emagrecimento podem ser agrupadas didaticamente de acordo com a proporção dos macronutrientes proposta (8). A tabela 1 descreve os principais grupos de dietas de acordo com sua composição nutricional e os nomes dos planos alimentares como são conhecidos popularmente. Embora muitas das dietas para emagrecimento sejam eficazes na redução ponderal em curto prazo, a avaliação qualitativa dessas dietas muitas vezes não é conhecida. De fato, a análise mais detalhada da composição nutricional dos planos alimentares propostos de dietas populares mostrou que nenhum deles alcança um adequado índice de alimentação saudável (7), conforme demonstrado na tabela 2 .
O índice de alimentação saudável constitui uma medida da qualidade da dieta por meio de um sistema de avaliação de 12 componentes (nove grupos alimentares e conteúdo total de gordura saturada, sódio e energia provenientes de gordura sólida, bebidas alcoólicas e açúcares) de acordo com as recomendações dietoterápicas americanas. Esse índice tem sido considerado um instrumento com amplo potencial de uso na epidemiologia nutricional, útil para a descrição e o monitoramento do padrão alimentar da população e para a avaliação das intervenções realizadas (9). A soma de todos os seus componentes totaliza um índice de alimentação saudável máximo de 100 pontos, sendo as dietas com escore total menor do que 51 pontos classificadas como "de baixa qualidade", com 51 a 80 pontos como "dietas que necessitam de melhorias", e as com mais do que 80 pontos, como "ótimas" (10).

As dietas propostas pelo "Dr. Ornish", "Vigilantes do Peso ${ }^{\circledR}$ rica em carboidratos" e a "Revolução da Glicose" [dieta com a escolha de alimentos com baixo índice glicêmico (IG) e carga glicêmica (CG)] parecem ter os maiores índices de alimentação saudável (tabela 2). O IG representa uma medida da qualidade do carboidrato contido nos alimentos, enquanto a CG expressa o produto do IG do alimento e seu conteúdo de carboidrato disponível (11). Em relação ao aporte energético, os planejamentos alimentares propostos por várias dietas oferecem importante restrição energética diária, geralmente inferior a $1.200 \mathrm{kcal} /$ dia (7). Entretanto, essas dietas podem ser deficientes em micronutrientes, com efeitos desfavoráveis no estado nutricional do paciente e também na redução da perda ponderal $(12,13)$.

\begin{tabular}{|c|c|c|c|c|}
\hline Tipo de dieta & $\begin{array}{l}\text { Lipídeos } \\
\text { (\% energia) }\end{array}$ & $\begin{array}{l}\text { Carboidratos } \\
\text { (\% energia) }\end{array}$ & $\begin{array}{l}\text { Proteínas } \\
\text { (\% energia) }\end{array}$ & Nomes populares \\
\hline Prudente & $20-30$ & $50-60$ & $15-20$ & $\begin{array}{c}\text { Vigilantes do Peso } \\
\text { Dieta LEARN }\end{array}$ \\
\hline Rica em gorduras com baixo teor de carboidratos & $55-65$ & $\begin{array}{c}<20 \\
(<100 \mathrm{~g} / \mathrm{dia})\end{array}$ & $25-30$ & $\begin{array}{l}\text { Dieta do Dr. Atkins's } \\
\text { "Revolução da glicose" } \\
\text { "Poder das proteínas" } \\
\text { "Vida sem pães" }\end{array}$ \\
\hline Moderada restrição de carboidratos e rica em proteínas & 30 & 40 & 30 & $\begin{array}{l}\text { South Beach } \\
\text { Ponto Z }\end{array}$ \\
\hline Baixo ou muito baixo teor de gorduras & $<10-19$ & $>65$ & $10-20$ & $\begin{array}{c}\text { Dieta do Dr. Ornish } \\
\text { "Coma mais, perca peso" }\end{array}$ \\
\hline
\end{tabular}

Fonte: Adaptado de Freedman e cols. (8). 


\begin{tabular}{|c|c|c|c|c|c|c|c|c|c|}
\hline \multirow{2}{*}{$\begin{array}{l}\text { Características das } \\
\text { dietas }\end{array}$} & \multirow{2}{*}{$\begin{array}{l}\text { Revolução } \\
\text { da glicose }\end{array}$} & \multicolumn{2}{|c|}{ Vigilantes do peso ${ }^{\circledR}$} & \multicolumn{2}{|c|}{ Atkins } & \multicolumn{2}{|c|}{ South Beach } & \multirow[b]{2}{*}{ Ponto Z } & \multirow[b]{2}{*}{ Ornish } \\
\hline & & $\begin{array}{c}\text { Rica em } \\
\text { carboidratos }\end{array}$ & $\begin{array}{l}\text { Rica em } \\
\text { proteínas }\end{array}$ & $\begin{array}{c}45 \mathrm{~g} \mathrm{de} \\
\text { carboidratos }\end{array}$ & $\begin{array}{c}100 \mathrm{~g} \text { de } \\
\text { carboidratos }\end{array}$ & Fase 2 & Fase 3 & & \\
\hline $\begin{array}{l}\text { IAS ajustado para } \\
\text { energia }\end{array}$ & $54,6 \pm 3,4$ & $60,4 \pm 3,5$ & $51,2 \pm 3,7$ & $41,6 \pm 3,2$ & $42,1 \pm 3,7$ & $53,0 \pm 3,3$ & $46,4 \pm 3,2$ & $54,9 \pm 3,9$ & $61,9 \pm 3,4$ \\
\hline \multicolumn{10}{|c|}{ Grupos alimentares (porções /dia) } \\
\hline Vegetais & $6,0 \pm 1,9$ & $6,3 \pm 1,2$ & $3,1 \pm 0,7$ & $6,6 \pm 1,1$ & $6,4 \pm 2,6$ & $11,1 \pm 5,8$ & $6,4 \pm 3,0$ & $7,2 \pm 2,0$ & $12,6 \pm 3,2$ \\
\hline Frutas & $5,1 \pm 1,4$ & $3,1 \pm 2,8$ & $2,4 \pm 2,3$ & $1,9 \pm 0,3$ & $3,0 \pm 0,4$ & $2,8 \pm 0,9$ & $2,5 \pm 1,2$ & $4,2 \pm 2,1$ & $4,7 \pm 2,0$ \\
\hline Nozes e proteína de soja & $4,1 \pm 1,7$ & $1,4 \pm 1,1$ & $1,3 \pm 1,2$ & $2,2 \pm 1,9$ & $3,1 \pm 2,4$ & $1,3 \pm 1,5$ & $0,4 \pm 0,4$ & $2,0 \pm 1,8$ & $2,1 \pm 1,2$ \\
\hline $\begin{array}{l}\text { Carnes branca e } \\
\text { vermelha }\end{array}$ & $1,5 \pm 1,9$ & $3,4 \pm 1,5$ & $2,3 \pm 2,1$ & $1,0 \pm 0,8$ & $1,2 \pm 1,4$ & $2,6 \pm 1,7$ & $2,5 \pm 2,2$ & $1,8 \pm 1,9$ & $4,0 \pm 0,0$ \\
\hline \multicolumn{10}{|c|}{ Composição nutricional } \\
\hline $\begin{array}{l}\text { Total de energia } \\
\text { (kcal/dia) }\end{array}$ & $1729 \pm 133$ & $1204 \pm 104$ & $1118 \pm 79$ & $1547 \pm 218$ & $1858 \pm 253$ & $1272 \pm 263$ & $1404 \pm 273$ & $1025 \pm 122$ & $1739 \pm 144$ \\
\hline $\begin{array}{l}\text { Carboidratos } \\
\text { (\% energia) }\end{array}$ & $57,1 \pm 3,1$ & $59,0 \pm 4,6$ & $52,9 \pm 4,1$ & $22,2 \pm 3,4$ & $29,5 \pm 5,1$ & $41,4 \pm 8,7$ & $37,0 \pm 10,2$ & $43,6 \pm 4,7$ & $81,0 \pm 2,3$ \\
\hline Proteínas (\% energia) & $19,5 \pm 1,4$ & $21,0 \pm 2,8$ & $25,8 \pm 4,5$ & $25,4 \pm 3,5$ & $20,7 \pm 3,1$ & $24,2 \pm 5,7$ & $25,7 \pm 5,3$ & $30,8 \pm 2,6$ & $15,9 \pm 1,6$ \\
\hline Lipídeos (\% energia) & $28,8 \pm 2,8$ & $25,7 \pm 2,2$ & $24,8 \pm 3,3$ & $54,9 \pm 5,7$ & $52,6 \pm 6,6$ & $37,4 \pm 8,8$ & $39,6 \pm 8,6$ & $29,2 \pm 3,9$ & $6,5 \pm 1,8$ \\
\hline $\begin{array}{l}\text { Saturados } \\
\text { (\% energia) }\end{array}$ & $5,3 \pm 1,0$ & $5,6 \pm 2,5$ & $6,0 \pm 2,6$ & $16,2 \pm 2,2$ & $17,6 \pm 3,5$ & $9,6 \pm 2,6$ & $10,4 \pm 3,1$ & $7,6 \pm 1,6$ & $1,5 \pm 0,6$ \\
\hline Trans (\% energia) & $0,4 \pm 04$ & $0,3 \pm 0,3$ & $0,3 \pm 0,3$ & $1,2 \pm 0,7$ & $1,3 \pm 0,4$ & $0,5 \pm 0,3$ & $0,6 \pm 0,3$ & $0,3 \pm 0,2$ & $0,3 \pm 0,2$ \\
\hline $\begin{array}{l}\text { Monoinsaturados } \\
\text { (\% energia) }\end{array}$ & $13,7 \pm 1,9$ & $11,2 \pm 1,7$ & $11,6 \pm 1,2$ & $21,9 \pm 4,3$ & $20,8 \pm 4,7$ & $16,0 \pm 4,3$ & $18,4 \pm 5,8$ & $13,5 \pm 1,5$ & $1,8 \pm 0,8$ \\
\hline $\begin{array}{l}\text { Poli-insaturados } \\
\text { n3 (\% energia) }\end{array}$ & $1,8 \pm 2,0$ & $1,2 \pm 0,7$ & $1,0 \pm 0,9$ & $3,4 \pm 0,7$ & $3,4 \pm 0,7$ & $2,7 \pm 2,3$ & $1,8 \pm 0,7$ & $1,3 \pm 0,9$ & $0,6 \pm 0,1$ \\
\hline $\begin{array}{l}\text { Poli-insaturados/ } \\
\text { saturados } \\
\text { (\% energia) }\end{array}$ & $1,6 \pm 0,7$ & $1,3 \pm 0,6$ & $1,0 \pm 0,4$ & $0,8 \pm 0,1$ & $0,6 \pm 0,2$ & $1,0 \pm 0,4$ & $0,9 \pm 0,4$ & $0,7 \pm 0,2$ & $0,7 \pm 0,2$ \\
\hline Fibras totais (g/dia) & $39,8 \pm 8,0$ & $34,7 \pm 9,3$ & $22,9 \pm 6,8$ & $22,1 \pm 4,4$ & $27,6 \pm 4,2$ & $26,0 \pm 9,0$ & $20,4 \pm 4,4$ & $21,8 \pm 3,2$ & $48,4 \pm 6,4$ \\
\hline $\begin{array}{l}\text { Fibras de cereais } \\
\text { (g/dia) }\end{array}$ & $8,3 \pm 7,6$ & $12,4 \pm 8,4$ & $8,5 \pm 5,9$ & $1,8 \pm 1,5$ & $6,9 \pm 3,4$ & $4,9 \pm 4,1$ & $6,2 \pm 5,4$ & $2,0 \pm 5,2$ & $11,3 \pm 9,0$ \\
\hline Sódio (mg/dia) & $1749 \pm 541$ & $1653 \pm 356$ & $1790 \pm 491$ & $2251 \pm 545$ & $2539 \pm 830$ & $1669 \pm 789$ & $1815 \pm 676$ & $1726 \pm 738$ & $2206 \pm 723$ \\
\hline
\end{tabular}

IAS: índice de alimentação saudável.

Fonte: Adaptado de Ma e cols. (7).

Em contrapartida às dietas populares, a comunidade científica tem concentrado esforços para encontrar a maneira mais coerente, saudável e prática para a perda e manutenção do peso corporal. Inúmeras publicações foram produzidas nos últimos dez anos (13). O fato de novas dietas ainda surgirem, tanto no meio acadêmico quanto em publicações não científicas, demonstra que ainda não está bem estabelecida qual a melhor estratégia dietoterápica para a perda de peso.

A mais recente revisão sistemática encontrada na literatura de Franz e cols. (13) ao avaliar dietas para emagrecimento revisou estudos publicados entre 1997 e setembro de 2004, acompanhada de metanálise de 80 ensaios clínicos randomizados (ECR) com pelo menos um ano de duração (13). Na tabela 3 estão descritas as intervenções avaliadas pela revisão citada, o número de estudos incluídos na revisão e o efeito na perda ponderal em 6, 12 e 48 meses de acompanhamento. As intervenções que envolveram redução energética e/ ou uso de medicação antiobesidade levaram à perda ponderal de $5 \%$ a $8 \%$ do peso inicial nos seis primeiros meses, com estabilização de peso a partir daí. Nos estudos com maior tempo de seguimento (até quatro anos), a média de perda ponderal obtida foi de $3 \%$ a $5,3 \%$ do peso inicial, sem recuperação do peso perdido.

Franz e cols. (13), em sua revisão, também descreveram uma perda ponderal de $8,5 \%$ do peso inicial em seis meses quando orientações específicas de prática de exercícios foram adicionadas às intervenções dietoterápicas, também com estabilização de peso ao final de 12 


\begin{tabular}{|c|c|c|c|c|}
\hline \multirow{2}{*}{ Descrição da intervenção } & \multirow{2}{*}{$\begin{array}{l}\text { Número de } \\
\text { estudos com a } \\
\text { intervenção }\end{array}$} & \multicolumn{3}{|c|}{ Perda ponderal (\% perda do peso inicial) ${ }^{\star}$} \\
\hline & & 6 meses & 12 meses & 48 meses \\
\hline Somente dieta com restrição energética & 51 & 5 & 4,6 & 3,0 \\
\hline Dieta e exercício físico & 17 & 8,5 & 4,0 & 4,0 \\
\hline Somente exercício & 6 & 2,7 & 1,0 & ND \\
\hline Substituiç̧ão de duas ou mais refeições por shake para obtenção de restrição energética & 7 & 9,6 & 7,5 & ND \\
\hline $\begin{array}{l}\text { Dietas de muito baixa caloria (< } 800 \mathrm{kcal} \text { ao dia, geralmente no início com dietas à base } \\
\text { de líquidos) }\end{array}$ & 11 & 16,0 & 10,0 & 5,0 \\
\hline Medicação antiobesidade: sibutramina & 7 & 8,4 & 8,4 & ND \\
\hline Medicação antiobesidade: orlistat & 13 & 8,0 & 8,0 & 5,3 \\
\hline $\begin{array}{l}\text { Somente orientações para perda de peso com encontro educativo anual em um braço } \\
\text { da randomização }\end{array}$ & 28 & 0 & 0 & 0 \\
\hline
\end{tabular}

* Efeito na perda de peso dos pacientes que completaram os estudos (não foram encontrados dados de intenção de tratamento em todos os estudos). ND: não descrito.

Fonte: Adaptado de Franz e cols. (13)

meses e manutenção de $4 \%$ de perda ponderal ao final de quatro anos de seguimento. Nos estudos com intervenções dietoterápicas de substituições de refeições ou com dietas muito restritas em energia, foi observada maior perda ponderal ao final de seis meses $(-9,6 \%$ e $-16 \%$ do peso inicial, respectivamente). Entretanto, esse tipo de intervenção foi acompanhado de rápida recuperação de peso aos 12 meses de seguimento. Em contrapartida, somente orientações gerais ou a prática de exercício físico isolada promoveram perda de peso mínima de até $2,7 \%$. É importante salientar que na citada revisão (13) não foram avaliadas a composição de macronutrientes e/ou a qualidade das dietas prescritas, e os resultados apresentados referem-se apenas àqueles pacientes que completaram os estudos.

Os dados disponíveis sobre as dietas para emagrecimento ainda não deixam claro de forma definitiva se, além da restrição energética, o tipo de dieta prescrita exerce influência na perda ponderal de pacientes com excesso de peso. Dessa forma, o presente manuscrito teve como objetivo revisar de forma sistemática o efeito na perda de peso corporal dos componentes dietéticos (macronutrientes e/ou alimentos) de dietas para emagrecimento em indivíduos adultos.

\section{MÉTODOS}

Para a presente revisão foram selecionados ECR no MedLine (língua portuguesa, inglesa e espanhola), além de publicações específicas da área médica e de nutrição de outubro de 2004 - após a publicação da revisão sis- temática de Franz e cols. (13) - até fevereiro de 2009 (descritores utilizados: diet e weight loss) concomitantemente por dois dos autores do presente manuscrito (JCA e TCR). Não foram incluídos estudos realizados e não publicados, resumos de eventos científicos (publicados ou não), dissertações e teses. Foram incluídos ECR com pelo menos um ano de acompanhamento que avaliaram o efeito de diferentes tipos de dietas na redução do peso corporal de indivíduos adultos. Foram excluídos estudos que avaliaram o efeito de medicações antiobesidade, cirurgias para obesidade ou que não atendiam ao objetivo proposto da presente revisão. O desfecho primário da presente revisão foi a variação de peso observada entre o início e o final do estudo. Em cada ECR, após a extração do dado original, a variação de peso foi apresentada como percentual do peso inicial. Foi definido como perda de peso adequada valor maior ou igual a $5 \%(12)$.

\section{RESULTADOS}

Vinte e três artigos preencheram os critérios de inclusão adotados na presente revisão sistemática (12,14-35). A figura 1 descreve o fluxograma da seleção dos estudos. Na tabela 4 estão descritas as principais características dos ECR de acordo com o tipo de dieta avaliada. O fator de impacto - segundo Journal Citation Report ${ }^{\circledR}$ 2007 (36) - dos estudos selecionados foi de 4,953 (mediana), variando de 1,612 a 52,589 . Setenta e oito por cento dos estudos foram publicados em periódicos com fator de impacto maior do que três, e cinco artigos fo- 
ram publicados no mesmo periódico (American Journal of Clinical Nutrition) com fator de impacto igual a $6,603(20-23,26,29)$. Doze $(52,2 \%)$ manuscritos apresentaram os resultados de acordo com o número de pacientes randomizados (método intention-to-treat) $(12,16,17,20-22,24-27,32,33,35)$, sete $(30,4 \%)$ apresentaram os dados somente dos participantes que completaram o estudo $(14,15,18,19,23,28,30)$, um manuscrito apresentou os resultados somente dos pacientes que preencheram os registros alimentares (30) e três manuscritos não descrevem como foi feita a análise dos resultados $(29,31,34)$.

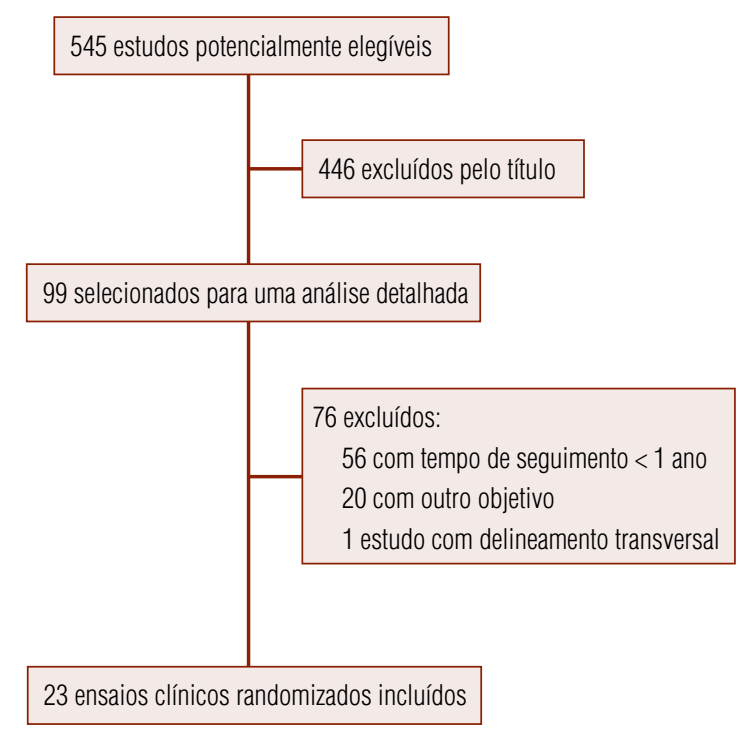

Figura 1. Fluxograma de seleção de estudos.

\section{Tipos de dietas}

Entre os 23 estudos selecionados (12,14-35), diferentes tipos de dietas foram utilizados para promoção de perda de peso. Na maioria das dietas $(66,1 \%)$ propostas, foram feitas restrições na oferta de energia diária $(12,14-17,19-21,23-26,28,29,32-35)$ ou restrição de determinado macronutriente: $14,3 \%$ das dietas contêm $<20 \%$ do total de energia diária proveniente de lipídeos $(12,22-24,27,29,35), 17,9 \%$ das dietas apresentam 30\% a $40 \%$ do total de energia diária proveniente de carboidratos $(12,18,24,25,33,35)$ e $7,1 \%$ das dietas contêm $<120 \mathrm{~g}$ de carboidratos ao dia $(12,18,24,32)$. Vinte e três por cento das dietas foram propostas sem restrição energética (ad libitum) (12,14,18,22,24,25,27,30). Em apenas um ECR não foi descrito se houve ou não restrição energética nas dietas propostas (31).
Em relação à distribuição dos macronutrientes, 19 $(34,0 \%)$ das 56 dietas avaliadas nos diferentes estudos apresentaram distribuição prudente, isto é, $50 \%$ a $60 \%$ da energia proveniente de carboidratos, $15 \%$ a $20 \%$ de proteínas e $20 \%$ a $30 \%$ de lipídeos $(14-17,20,24,27,28,31$ $34)$. Em três desses estudos $(15,16,19)$, houve a substituição de uma ou duas refeições por sopas, bebidas tipo shake ou barras de cereal enriquecidas com micronutrientes. Na maioria das dietas prudentes, houve restrição energética (12,15-17,19,28,31-34).

Além da proporção de macronutrientes nas dietas, o efeito de diferentes fontes alimentares na perda de peso também foi avaliado (19 dietas) por meio de dieta ovolactovegetariana restrita em energia (20), dieta vegetariana estrita (tipo vegano) e com baixo teor de lipídeos $(12,27)$, dieta com alimentos de diferentes IG $(17,21,26,28,31,35)$ ou baixa carga glicêmica (CG) (22), dietas com 2 a 4 fontes alimentares de cálcio e fibras (17) ou dieta com óleo vegetal rico em diacilglicerol ad libitum para o preparo dos alimentos (30). Em um dos estudos, não foi descrita a distribuição de macronutrientes das dietas (20). Das 19 dietas que avaliaram efeito de diferentes fontes alimentares na perda de peso, metade apresentou também restrição energética $(17,20-22,26,28)$.

Entre as dietas propostas com baixo teor de lipídeos, algumas também incentivaram o consumo de frutas e vegetais (23) ou frutas, vegetais e grãos (27), com (23) e sem restrição da energia proveniente da dieta (27). O efeito do padrão alimentar tipo mediterrâneo com restrição energética na perda de peso foi avaliado em um estudo (32).

Indivíduos em estudo, seguimento, taxa de abandono e aderência

Oito estudos foram conduzidos somente com participantes do sexo feminino $(18,19,23,26,27,29,31,34)$ e somente um deles incluiu participantes com IMC dentro da faixa de normalidade (26). Apenas três estudos apresentaram tempo de seguimento igual ou superior a dois anos $(14,32,35)$ e 14 estudos apresentaram taxa de abandono igual ou superior a $25 \%$ em pelo menos um dos tipos de dieta em estudo (12,14$16,18-20,22,23,26,28,29,33,35)$. Um manuscrito não descreveu as perdas de seguimento do estudo (31) e um ECR não descreveu as perdas por grupo de dieta, mas apenas em relação ao total de pacientes randomizados (15). 
Tabela 4. Ensaios clínicos randomizados que compararam o efeito de diferentes dietas de emagrecimento na perda de peso de indivíduos adultos (2007 a 2009)

\begin{tabular}{|c|c|c|c|c|c|}
\hline $\begin{array}{c}\text { Autores } \\
\text { Revista, ano }\end{array}$ & $\begin{array}{l}\text { Amostra em } \\
\text { estudo }\end{array}$ & $\begin{array}{l}\text { Duração } \\
\text { do estudo }\end{array}$ & Dietas propostas & $\begin{array}{l}\text { Redução ponderal } \\
\text { em relação ao } \\
\text { peso inicial }\end{array}$ & $\begin{array}{c}\text { Taxa de abandono } \\
\text { e instrumento(s) de medida } \\
\text { de aderência à dieta }\end{array}$ \\
\hline \multicolumn{6}{|c|}{ Dietas com distribuição prudente de macronutrientes } \\
\hline $\begin{array}{l}\text { Li e cols. } \\
\text { Eur J Clin Nutr. } \\
2005(15)\end{array}$ & $\begin{array}{c}n=104 \\
29,8 \% \text { de } \\
\text { mulheres } \\
\text { DM tipo } 2 \\
(\text { HbA1c } 7 \%-12 \%) \\
>30 \text { anos } \\
\text { IMC } 27-40 \mathrm{~kg} / \mathrm{m}^{2}\end{array}$ & 12 meses & $\begin{array}{l}\text { Dietas com restrição energética de } \\
500 \text { kcal/dia: } \\
\text { Intervenção: substituição gradativa } \\
\text { de 1-3 refeições do dia por bebidas } \\
\text { à base de soja tipo shakes (Slim } \\
\text { Fast }{ }^{\circledR} \text { ), estímulo ao consumo de } \\
\text { frutas e vegetais } \\
\text { Controle (prudente): } 55 \%-65 \% \text { de } \\
\text { energia de carboidratos, } 10 \%-20 \% \text { de } \\
\text { proteínas e } 30 \% \text { de lipídeos }\end{array}$ & $\begin{array}{l}\text { Perda de peso significativa } \\
\text { (modesta) e maior na dieta } \\
\text { intervenção em relação à dieta } \\
\text { controle: } \\
\text { Intervenção: } 4,6 \% \\
\text { Controle (prudente): } 2,3 \% \\
\text { * Analisados somente os pacientes } \\
\text { que finalizaram o estudo }\end{array}$ & $\begin{array}{l}\text { Perdas de seguimento (geral) } \\
\text { de } 26 \% \\
\text { Recordatórios de } 24 \text { horas } \\
\text { bimestrais }\end{array}$ \\
\hline $\begin{array}{l}\text { Rolls e cols. } \\
\text { Obes Res. } 2005 \\
(16)\end{array}$ & $\begin{array}{c}\mathrm{n}=200 \\
77 \% \text { de } \\
\text { mulheres } \\
20-65 \text { anos } \\
\quad \mathrm{MC}= \\
26-40 \mathrm{~kg} / \mathrm{m}^{2}\end{array}$ & 12 meses & $\begin{array}{l}\text { Dietas prudentes com restrição } \\
\text { energética de } 750 \text { kcal/dia: } \\
\text { Intervenção ( } 2 \text { X sopa): substituição } \\
\text { de } 2 \text { refeições por sopa de 100 } \\
\text { kcal/porção } \\
\text { Intervenção ( } 1 \text { X sopa): substituição } \\
\text { de } 1 \text { refeição por sopa de } 100 \text { kcal/ } \\
\text { porção } \\
\text { Intervenção (2 X lanche): } \\
\text { substituição de } 2 \text { refeições por } \\
\text { lanches de } ~ 100 \text { kcal/porção } \\
\text { Controle (prudente): 55\% de energia } \\
\text { de carboidratos, } 15 \% \text { de proteínas e } \\
30 \% \text { de lipídeos, nenhum alimento } \\
\text { específico }\end{array}$ & $\begin{array}{l}\text { Perda de peso significativa e maior } \\
\text { na dieta com } 2 \text { X sopa em relação à } \\
\text { dieta com } 2 \text { X lanches, sem } \\
\text { diferença com as outras dietas: } \\
\text { Intervenção ( } 2 \text { X sopa): } 7,2 \% \\
\text { Intervenção ( } 1 \text { X sopa): } 6,1 \% \\
\text { Intervenção ( } 2 \text { X lanche): } 5,0 \% \\
\text { Controle (prudente): } 8,2 \% \\
\text { * Analisados todos os pacientes } \\
\text { randomizados }\end{array}$ & $\begin{array}{l}\text { Intervenção (2 X sopa): } 32 \% \\
\text { Intervenção (1 X sopa): } 22 \% \\
\text { Intervenção ( } 2 \text { X lanche): } 26 \% \\
\text { Controle (prudente): } 26 \% \\
\text { Registros alimentares de } 3 \text { dias } \\
\text { quinzenais nos primeiros } 6 \text { meses } \\
\text { e mensais nos últimos } 6 \text { meses }\end{array}$ \\
\hline $\begin{array}{l}\text { Ashley e cols. } \\
\text { Nutrition J. } 2007 \\
\text { (19) }\end{array}$ & $\begin{array}{c}n=96 \\
\text { Mulheres } \\
25-50 \text { anos } \\
\text { IMC } 25-35 \mathrm{~kg} / \mathrm{m}^{2}\end{array}$ & 12 meses & $\begin{array}{l}\text { Dietas prudentes com restrição } \\
\text { energética ( } 1.200 \text { kcal ao dia): } \\
\text { Intervenção: substituição de 1-2 } \\
\text { refeições do dia por bebidas tipo } \\
\text { shakes e/ou barras enriquecidas } \\
\text { com vitaminas e minerais } \\
\text { Controle: } 50 \% \text { de energia de } \\
\text { carboidratos, } 19 \% \text { de proteínas e } \\
31 \% \text { de lipídeos }\end{array}$ & $\begin{array}{l}\text { Perda de peso significativa e não } \\
\text { diferente entre as dietas: } \\
\text { Controle: } 7,7 \% \\
\text { Intervenção: } 6,3 \% \\
\text { * Analisados somente os pacientes } \\
\text { que finalizaram o estudo }\end{array}$ & $\begin{array}{l}\text { Intervenção: } 27 \% \\
\text { Controle: } 27 \% \\
\text { Registros alimentares de } 3 \text { dias a } \\
\text { cada } 6 \text { meses }\end{array}$ \\
\hline $\begin{array}{l}\text { Villareal e cols. } \\
\text { JCEM. } 2008 \text { (34) }\end{array}$ & $\begin{array}{c}n=27 \\
\text { Mulheres } \\
\geq 65 \text { anos } \\
I M C \geq 30 \mathrm{~kg} / \mathrm{m}^{2}\end{array}$ & 12 meses & $\begin{array}{l}\text { Intervenção: restrição energética de } \\
500-750 \text { kcal/dia; } 50 \% \text { de energia } \\
\text { de carboidratos, 30\% de lipídeos e } \\
20 \% \text { de proteínas } \\
\text { Controle: dieta habitual, sem } \\
\text { restrição kcal/dia }\end{array}$ & $\begin{array}{l}\text { Perda de peso somente na dieta } \\
\text { intervenção: } \\
\text { Intervenção: }-10 \pm 2 \% \\
\text { Controle: }+1,2 \pm 1,3 \% \\
\text { * Não há descrição se as análises } \\
\text { foram feitas com todos os pacientes } \\
\text { randomizados ou somente os que } \\
\text { completaram o estudo }\end{array}$ & $\begin{array}{l}\text { Intervenção: } 11,7 \% \\
\text { Controle: } 10 \% \\
\text { Não há medida de aderência } \\
\text { especificada }\end{array}$ \\
\hline \multicolumn{6}{|c|}{ Dietas ricas em proteínas (> $20 \%$ do total de energia diária) com restrição de carboidratos } \\
\hline $\begin{array}{l}\text { Due e cols. } \\
\text { Int J Obes. } 2004 \\
\text { (14) }\end{array}$ & $\begin{array}{c}\mathrm{n}=50 \\
76 \% \text { de } \\
\text { mulheres } \\
18-56 \text { anos } \\
\text { IMC } 25-35 \mathrm{~kg} / \mathrm{m}^{2}\end{array}$ & 24 meses & $\begin{array}{l}\text { Dietas ad libitum com } 30 \% \text { de } \\
\text { energia proveniente de lipídeos: } \\
\text { Controle (prudente): } 12 \% \text { de } \\
\text { energia de proteínas } \\
\text { Intervenção (rica em proteínas): } \\
25 \% \text { de energia de proteínas }\end{array}$ & $\begin{array}{l}\text { Perda de peso significativa sem } \\
\text { diferença entre as dietas: } \\
\text { Controle (prudente): } 4,9 \% \\
\text { Intervenção (rica em proteínas): } \\
6,4 \% \\
{ }^{*} \text { Analisados somente os pacientes } \\
\text { que finalizaram o estudo }\end{array}$ & $\begin{array}{l}\text { Controle (prudente): } 28 \% \\
\text { Intervenção (rica em proteínas): } \\
8 \% \\
\text { Registros alimentares de } 7 \text { dias } \\
\text { trimestrais e medidas mensais de } \\
\text { excreção de ureia urinária (24h) }\end{array}$ \\
\hline
\end{tabular}


Tabela 4. Ensaios clínicos randomizados que compararam o efeito de diferentes dietas de emagrecimento na perda de peso de indivíduos adultos (2007 a 2009) (continuação)

\begin{tabular}{|c|c|c|c|c|c|}
\hline $\begin{array}{c}\text { Autores } \\
\text { Revista, ano }\end{array}$ & $\begin{array}{c}\text { Amostra em } \\
\text { estudo }\end{array}$ & $\begin{array}{l}\text { Duração } \\
\text { do estudo }\end{array}$ & Dietas propostas & $\begin{array}{l}\text { Redução ponderal } \\
\text { em relação ao } \\
\text { peso inicial }\end{array}$ & $\begin{array}{l}\text { Taxa de abandono } \\
\text { e instrumento(s) de medida } \\
\text { de aderência à dieta }\end{array}$ \\
\hline $\begin{array}{l}\text { McAuley e cols. } \\
\text { Int J Obes. } 2006 \\
\text { (18) }\end{array}$ & $\begin{array}{c}\mathrm{n}=93 \\
\text { Mulheres } \\
\text { Escore de } \\
\text { sensibilidade à } \\
\text { ação da insulina } \\
\text { após TOTG: } \\
\text { insulina } \\
<6,3 \mathrm{G} \text { mlU }{ }^{-1} \mathrm{i}^{-1} \\
30-70 \text { anos } \\
\text { IMC }>27 \mathrm{~kg} / \mathrm{m}^{2}\end{array}$ & $2 \mathrm{~m}$ & $\begin{array}{l}\text { Dietas ad libitum: } \\
\text { Baixo teor de carboidratos: } \\
\leq 50 \text { g de carboidratos } \\
\text { Dieta rica em proteínas (Ponto Z): } \\
\text { 40\% de energia de carboidratos } \\
\text { com baixo IG, 30\% de proteínas e } \\
30 \% \text { de lipídeos (preferencialmente } \\
\text { monoinsaturados); } 5 \text { refeições } \\
\text { diárias } \\
\text { Controle: baseada nas } \\
\text { recomendações da Associação } \\
\text { Européia de Diabetes }\end{array}$ & $\begin{array}{l}\text { Perda de peso significativa e maior } \\
\text { na dieta restrita em carboidratos e } \\
\text { dieta rica em proteínas em relação } \\
\text { ao controle: } \\
\text { Baixo teor de carboidratos: } 8,2 \% \\
\text { Dieta rica em proteínas } \\
\text { (Ponto Z): } 7,0 \% \\
\text { Controle: } 4,7 \% \\
{ }^{*} \text { Analisados somente os pacientes } \\
\text { que finalizaram o estudo }\end{array}$ & $\begin{array}{l}\text { Baixo teor de carboidratos: } \\
22,6 \% \\
\text { Dieta rica em proteínas } \\
\text { (Ponto Z): } 6,7 \% \\
\text { Controle: } 25 \% \\
\text { Registros alimentares de } 3 \text { dias, } \\
\text { escala analógica do apetite antes e } \\
\text { depois de refeições em } 3 \text { dias, } \\
\text { questionário para avaliação do } \\
\text { humor e de dificuldades do } \\
\text { seguimento da dieta a cada } \\
6 \text { meses }\end{array}$ \\
\hline
\end{tabular}

$\begin{array}{lccl}\text { Clifton e cols. } & n=79 & 16 \text { meses } & \text { Dietas com } 1.400 \mathrm{kcal} / \mathrm{dia} e<10 \% \\ \text { Am J Clin Nutr. } & \text { Mulheres } & \text { de energia de saturados: } \\ 2008(29) & 49 \pm 9 \text { anos } & \text { Rica em proteínas: } 34 \% \text { de energia } \\ & \text { IMC } 32,8 \pm & \text { de proteínas, } 46 \% \text { de carboidratos e } \\ & 3,5 \mathrm{~kg} / \mathrm{m}^{2} & & 20 \% \text { de lipídeos } \\ & & \text { Rica em carboidratos: } 64 \% \\ & \text { de energia de carboidratos, } 17 \% \\ & \text { de proteínas } 20 \% \text { de lipídeos }\end{array}$

Perda de peso significativa e não diferente entre as dietas:

Rica em proteínas: 5,4\%

Rica em carboidratos: 5,1\%

* Não há descrição se as análises foram feitas com todos os pacientes randomizados ou somente os que completaram o estudo
Rica em proteínas: $29,3 \%$ Rica em carboidratos: $37,7 \%$ Razão de ureia-creatinina urinárias coletadas a cada visita

* Os valores não foram diferentes entre os dois grupos, sugerindo baixa aderência na alocação das dietas

\section{Dietas com redução do índice glicêmico e/ou carga glicêmica}

\begin{tabular}{|c|c|c|c|c|c|}
\hline $\begin{array}{l}\text { Das e cols. } \\
\text { Am J Clin Nutr. } \\
2007 \text { (21) }\end{array}$ & $\begin{array}{c}\mathrm{n}=34 \\
\text { Adultos } \\
24-42 \text { anos } \\
\text { IMC } 25-30 \mathrm{~kg} / \mathrm{m}^{2}\end{array}$ & 12 meses & $\begin{array}{l}\text { Dietas com restrição energética de } \\
30 \% \text { do total de kcal/dia: } \\
\text { Alto IG: } 60 \% \text { de energia de } \\
\text { carboidratos, } 20 \% \text { de proteínas, } \\
20 \% \text { de lipídeos e IG = } 85,6 \% \\
\text { Baixo IG: } 40 \% \text { de energia de } \\
\text { carboidratos, } 30 \% \text { de proteínas, } \\
30 \% \text { de lipídeos e IG = 52,4\% } \\
\text { * Alimento referência para cálculo } \\
\text { do IG: não especificado }\end{array}$ & $\begin{array}{l}\text { Perda de peso significativa nas } \\
\text { dietas e não diferente entre as } \\
\text { dietas: } \\
\text { Alto IG: } 8,0 \pm 4,1 \% \\
\text { Baixo IG: } 7,8 \pm 5,0 \% \\
\text { *Analisados todos os pacientes } \\
\text { randomizados }\end{array}$ & $\begin{array}{l}\text { Alto IG: } 11,8 \% \\
\text { Baixo IG: } 17,6 \% \\
\text { Gasto energético medido por água } \\
\text { duplamente marcada e taxa de } \\
\text { metabolismo basal por calorimetria } \\
\text { indireta avaliados trimestralmente }\end{array}$ \\
\hline $\begin{array}{l}\text { Ebbeling e cols. } \\
\text { JAMA. } 2007 \text { (22) }\end{array}$ & $\begin{array}{c}n=73 \\
79,5 \% \text { mulheres } \\
18-35 \text { anos } \\
\text { IMC } \geq 30 \mathrm{~kg} / \mathrm{m}^{2} \\
\text { e peso corporal } \\
<140 \mathrm{~kg} \\
\text { Estratificados de } \\
\text { acordo com a } \\
\text { resposta } \\
\text { insulinêmica } 30 \\
\text { minutos após } \\
\text { TOTG }\end{array}$ & 18 meses & $\begin{array}{l}\text { Dietas ad libitum: } \\
\text { Baixa CG: } 40 \% \text { de energia de } \\
\text { carboidratos com ênfase aos } \\
\text { alimentos de baixa CG (40 e } \\
50 \mathrm{~g} / 1.000 \text { kcal) e } 35 \% \text { de lipídeos } \\
\text { Baixo teor de lipídeos: } 55 \% \\
\text { de energia de carboidratos, } 20 \% \\
\text { de lipídeos e CG entre } 60 \text { e } \\
75 \text { g/ } 1.000 \text { kcal } \\
\text { * Alimento referência para cálculo } \\
\text { do IG: glicose }\end{array}$ & $\begin{array}{l}\text { Perda de peso significativa nas } \\
\text { dietas e diferente entre as dietas } \\
\text { somente no grupo de pacientes com } \\
\text { valores mais altos de insulinemia: } \\
\text { Baixa CG: } 5,6 \% \\
\text { Baixo teor de lipídeos: } 1,2 \% \\
{ }^{*} \text { Analisados todos os pacientes } \\
\text { randomizados }\end{array}$ & $\begin{array}{l}\text { Baixa CG: } 22,2 \% \\
\text { Baixo teor de lipídeos: } 37,8 \% \\
\text { Três recordatórios de } 24 \text { horas } \\
\text { aplicados por telefone } \\
\text { semestralmente }\end{array}$ \\
\hline $\begin{array}{l}\text { Sichieri e cols. } \\
\text { Am J Clin Nutr. } \\
2007 \text { (26) }\end{array}$ & $\begin{array}{c}n=414 \\
\text { Mulheres } \\
25-45 \text { anos } \\
\text { IMC } 23-29,9 \mathrm{~kg} / \mathrm{m}^{2}\end{array}$ & 18 meses & $\begin{array}{l}\text { Dietas com restrição energética de } \\
100 \text { a } 300 \text { kcal/dia e com 26\%-28\% } \\
\text { da energia de lipídeos: } \\
\text { Alto IG: dieta habitual dos } \\
\text { participantes } \\
\text { Baixo IG: redução de } 40 \text { unidades } \\
\text { do IG das refeições em relação à } \\
\text { dieta de alto IG } \\
\text { * Alimento referência para cálculo } \\
\text { do IG: pão branco }\end{array}$ & $\begin{array}{l}\text { Perda de peso significativa } \\
\text { (pequena) e sem diferença entre as } \\
\text { dietas: } \\
\text { Alto IG: 0,59\% } \\
\text { Baixo IG: } 0,38 \% \\
{ }^{\star} \text { Analisados todos os pacientes } \\
\text { randomizados }\end{array}$ & $\begin{array}{l}\text { Alto IG: } 41 \% \\
\text { Baixo IG: } 38 \% \\
\text { Escala pontuada de acordo com } \\
\text { componentes específicos do } \\
\text { questionário de frequência } \\
\text { alimentar aplicado }\end{array}$ \\
\hline
\end{tabular}


Tabela 4. Ensaios clínicos randomizados que compararam o efeito de diferentes dietas de emagrecimento na perda de peso de indivíduos adultos (2007 a 2009 ) (continuação)

\begin{tabular}{|c|c|c|c|c|c|}
\hline $\begin{array}{c}\text { Autores } \\
\text { Revista, ano }\end{array}$ & $\begin{array}{c}\text { Amostra em } \\
\text { estudo }\end{array}$ & $\begin{array}{l}\text { Duração } \\
\text { do estudo }\end{array}$ & Dietas propostas & $\begin{array}{l}\text { Redução ponderal } \\
\text { em relação ao } \\
\text { peso inicial }\end{array}$ & $\begin{array}{l}\text { Taxa de abandono } \\
\text { e instrumento(s) de medida } \\
\text { de aderência à dieta }\end{array}$ \\
\hline \multicolumn{6}{|c|}{ Dietas com diferentes fontes alimentares } \\
\hline $\begin{array}{l}\text { Thompson e } \\
\text { cols. } \\
\text { Obes Res. } 2005 \\
\text { (17) }\end{array}$ & $\begin{array}{c}\mathrm{n}=90 \\
86,6 \% \text { de } \\
\text { mulheres } \\
25-70 \text { anos } \\
\text { IMC } 30-40 \mathrm{~kg} / \mathrm{m}^{2}\end{array}$ & 12 meses & $\begin{array}{l}\text { Dietas com restrição energética de } \\
500 \text { kcal/dia: } \\
\text { Controle: } 30 \% \text { de energia de } \\
\text { lipídeos, } 20 \% \text { de proteínas e } 50 \% \\
\text { de carboidratos com } 2 \text { porções } \\
\text { alimentares de fontes de cálcio e } \\
\text { fibras } \\
\text { Rica em laticínios: idem controle + } 4 \\
\text { porções alimentares de cálcio e } \\
\text { fibras (2 porções de leite) } \\
\text { Rica em laticínios, rica em fibras e } \\
\text { baixo IG: idem dieta rica em } \\
\text { laticínios + fibras (grãos, frutas e } \\
\text { vegetais) e redução do consumo de } \\
\text { alimentos com alto IG (IG > 100\% } \\
\text { foram fortemente desencorajados) }\end{array}$ & $\begin{array}{l}\text { Perda de peso foi significativa, mas } \\
\text { não diferente entre as } 3 \text { dietas: } \\
\text { Controle: } 9,3 \% \\
\text { Rica em laticínios: } 8,9 \% \\
\text { Rica em laticínios, rica em fibras e } \\
\text { baixo IG: 8,9\% } \\
\text { * Foram analisados todos os } \\
\text { pacientes randomizados }\end{array}$ & $\begin{array}{l}\text { Controle: } 10,3 \% \\
\text { Rica em laticínios: } 23,3 \% \\
\text { Rica em laticínios, rica em fibras e } \\
\text { baixo IG: } 22,6 \% \\
\text { Registros alimentares de } 3 \text { dias }\end{array}$ \\
\hline $\begin{array}{l}\text { Burke e cols. } \\
\text { Am J Nutr. } 2007 \\
\text { (20) }\end{array}$ & $\begin{array}{c}n=200 \\
87 \% \text { mulheres } \\
18-55 \text { anos } \\
\text { IMC } 27-43 \mathrm{~kg} / \mathrm{m}^{2}\end{array}$ & 18 meses & $\begin{array}{l}\text { Dietas com restrição energética } \\
\text { (1.200 kcal para mulheres e } \\
1.500 \text { kcal para homens): } \\
\text { Ovolactovegetariana: retirada de } \\
\text { carne, aves, peixe e derivados } \\
\text { Controle (onívora): restrição de } \\
\text { alimentos ricos em gordura } \\
\text { * Manuscrito não descreve a } \\
\text { composição nutricional das dietas } \\
\text { prescritas, somente da ingestão } \\
\text { relatada pelos pacientes, de acordo } \\
\text { com o tipo de dieta e a preferência }\end{array}$ & $\begin{array}{l}\text { Perda de peso significativa nas } \\
\text { dietas: } \\
\text { Pacientes que preferiam a dieta } \\
\text { na qual foram randomizados: } \\
\text { Ovolactovegetariana: } \\
5,3 \pm 6,2 \% \\
\text { Onívora: } 3,9 \pm 6 \% \\
\text { Pacientes que não preferiam a dieta } \\
\text { na qual foram randomizados: } \\
\text { Ovolactovegetariana: } \\
8,0 \pm 7,8 \% \\
\text { Onívora: } 7,9 \pm 8,1 \% \\
\text { Perda de peso com associação } \\
\text { negativa limítrofe com dieta } \\
\text { preferida ( } p=0,06 \text { ) } \\
\text { * Analisados todos os pacientes } \\
\text { randomizados }\end{array}$ & $\begin{array}{l}\text { Ovolactovegetariana: } 25 \% \\
\text { Onívora: } 22 \% \\
\text { Registros alimentares de } 3 \text { dias a } \\
\text { cada } 6 \text { meses }\end{array}$ \\
\hline
\end{tabular}

\begin{tabular}{|c|c|c|c|c|c|}
\hline $\begin{array}{l}\text { Ello-Martin e } \\
\text { cols. } \\
\text { Am J Nutr. } 2007 \\
\text { (23) }\end{array}$ & $\begin{array}{c}n=97 \\
\text { Mulheres } \\
20-60 \text { anos } \\
\text { IMC 30-40 kg/m² }\end{array}$ & 12 meses & $\begin{array}{l}\text { Dietas com restrição energética de } \\
\text { 500 kcal/dia: } \\
\text { Intervenção: baixo teor de lipídeos } \\
(29,5 \pm 5,1 \mathrm{~g} / \text { dia) e maior consumo } \\
\text { de frutas e vegetais } \\
\text { ( } 26 \mathrm{~g} / \text { dia) } \\
\text { Controle: baixo teor de lipídeos } \\
\text { (25,5 } \pm 5,5 \mathrm{~g} / \text { dia) }\end{array}$ & $\begin{array}{l}\text { Perda de peso significativa e maior } \\
\text { na dieta intervenção em relação à } \\
\text { dieta controle: } \\
\text { Intervenção: } 8,7 \% \\
\text { Controle: } 7,1 \% \\
\text { * Analisados somente os pacientes } \\
\text { que completaram o estudo }\end{array}$ & $\begin{array}{l}\text { Intervenção: } 27,1 \% \\
\text { Controle: } 26,5 \% \\
\text { Registros alimentares de } 3 \text { dias } \\
\text { quinzenalmente na fase } 1 \text { e } \\
\text { mensalmente na fase 2, além de } \\
\text { escalas analógicas para avaliação } \\
\text { de fome, saciedade e questionário } \\
\text { específico para grau de satisfação } \\
\text { da dieta }\end{array}$ \\
\hline $\begin{array}{l}\text { Turner-McGrievy } \\
\text { e cols. } \\
\text { Obesity. } 2007 \\
\text { (27) }\end{array}$ & $\begin{array}{c}\mathrm{n}=64 \\
\text { Mulheres } \\
\text { pós-menopáusicas } \\
\text { IMC 26-44 kg/m² }\end{array}$ & 24 meses & $\begin{array}{l}\text { Dietas sem restrição energética: } \\
\text { Tipo vegano com baixo teor de } \\
\text { lipídeos: baseada em frutas, } \\
\text { vegetais, leguminosas e grãos. } \\
\text { Cereais refinados foram } \\
\text { desencorajados e produtos animais, } \\
\text { excluídos } \\
\text { Controle: baseada nas Diretrizes do } \\
\text { NCEP ATP III }\end{array}$ & $\begin{array}{l}\text { Perda de peso significativa e maior } \\
\text { na dieta tipo vegano: } \\
\text { Tipo vegano com baixo teor de } \\
\text { lipídeos: } 3,5 \% \\
\text { Controle: } 0,9 \% \\
\text { *As participantes que receberam } \\
\text { grupo de apoio ( } 64,8 \% \text { do total) } \\
\text { perderam mais peso do que as que } \\
\text { não receberam } \\
\text { *Analisados todos os pacientes } \\
\text { randomizados }\end{array}$ & $\begin{array}{l}\text { Tipo vegano com baixo teor de } \\
\text { lipídeos: } 16,1 \% \\
\text { Controle: } 12,9 \% \\
\text { Escala construída baseada nas } \\
\text { porções alimentares obtidas em } \\
\text { questionário de frequência } \\
\text { alimentar }\end{array}$ \\
\hline
\end{tabular}




\begin{tabular}{|c|c|c|c|c|c|}
\hline $\begin{array}{c}\text { Autores } \\
\text { Revista, ano }\end{array}$ & $\begin{array}{l}\text { Amostra em } \\
\text { estudo }\end{array}$ & $\begin{array}{l}\text { Duração } \\
\text { do estudo }\end{array}$ & Dietas propostas & $\begin{array}{c}\text { Redução ponderal } \\
\text { em relação ao } \\
\text { peso inicial }\end{array}$ & $\begin{array}{l}\text { Taxa de abandono } \\
\text { e instrumento(s) de medida } \\
\text { de aderência à dieta }\end{array}$ \\
\hline $\begin{array}{l}\text { Kawashima e } \\
\text { cols. } \\
\text { J Am Diet Assoc. } \\
2008 \text { (30) }\end{array}$ & $\begin{array}{c}\mathrm{n}=312 \\
58,9 \% \text { de } \\
\text { mulheres } \\
22-73 \text { anos } \\
>25 \mathrm{~kg} / \mathrm{m}^{2} \mathrm{e} / \mathrm{ou} \\
\text { triglicerídeos } \\
>150 \mathrm{mg} / \mathrm{dL}\end{array}$ & 12 meses & $\begin{array}{l}\text { Dietas ad libitum: } \\
\text { Intervenção: uso ad libitum de óleo } \\
\text { vegetal rico em diglicerídeos no } \\
\text { preparo dos alimentos } \\
\text { Controle: uso ad libitum de óleo } \\
\text { vegetal rico em triglicerídeos no } \\
\text { preparo dos alimentos } \\
{ }^{\star} 0 \text { óleo vegetal foi fornecido aos } \\
\text { participantes }\end{array}$ & $\begin{array}{l}\text { Perda de peso significativa } \\
\text { (pequena) e maior na dieta } \\
\text { intervenção: } \\
\text { Intervenção: } 1,2 \% \\
\text { Controle: } 0,4 \% \\
\text { Participantes obesos tiveram uma } \\
\text { maior perda ponderal com uso de } \\
\text { diglicerídeos } \\
\text { *Analisados somente os pacientes que } \\
\text { entregaram os registros alimentares }\end{array}$ & $\begin{array}{l}\text { Intervenção: } 8,9 \% \\
\text { Controle: } 13,5 \% \\
\text { Registros alimentares para } \\
\text { determinação da quantidade de } \\
\text { óleo consumida aplicados a cada } \\
\text { visita }\end{array}$ \\
\hline \multicolumn{6}{|c|}{ Diferentes tipos de dietas (miscelânea) } \\
\hline $\begin{array}{l}\text { Dansinger e } \\
\text { cols. } \\
\text { JAMA. } 2005 \text { (12) }\end{array}$ & $\begin{array}{c}n=160 \\
51 \% \text { de } \\
\text { mulheres } \\
\text { 22-72 anos } \\
\text { IMC 27-42 kg/m² }\end{array}$ & 12 meses & $\begin{array}{l}\text { Baixo teor de carboidratos: } \\
<20 \mathrm{~g} / \text { dia de carboidratos } \\
\text { Ponto Z: } 40 \% \text { de energia de } \\
\text { carboidratos, 30\% de proteínas e } \\
30 \% \text { de lipídeos } \\
\text { Vigilantes do peso } 0^{\circledast} \text {. dietas com } \\
1.200-1.600 \mathrm{kcal} / \text { dia em um sistema } \\
\text { de pontos } \\
\text { Vegetariana com baixo teor lipídeos: } \\
<10 \% \text { de lipídeos } \\
\text { * Sem diferença significativa da } \\
\text { ingestão de kcal/dia entre as dietas }\end{array}$ & $\begin{array}{l}\text { Perda de peso significativa } \\
\text { (modesta) sem diferença entre as } \\
\text { dietas: } \\
\text { Baixo teor de carboidratos: } 2,1 \% \\
\text { Ponto Z: } 3,2 \% \text {. } \\
\text { Vigilantes do peso }{ }^{\circledR:} 3,1 \% \text {. } \\
\text { Vegetariana com baixo teor lipídeos: } \\
3,2 \% \\
{ }^{*} \text { Analisados todos os pacientes } \\
\text { randomizados }\end{array}$ & $\begin{array}{l}\text { Baixo teor de carboidratos: } 47,5 \% \\
\text { Ponto Z: } 35 \% \\
\text { Vigilantes do peso } 0^{\circledR}: 35 \% \\
\text { Vegetariana com baixo teor } \\
\text { lipídeos: } 50 \% \\
\text { Registros alimentares de } 3 \text { dias a } \\
\text { cada visita ( } 0,2,6 \text { e } 12 \text { meses) e } \\
\text { autorrelato de aderência }\end{array}$ \\
\hline $\begin{array}{l}\text { Gardner e cols. } \\
\text { JAMA. } 2007 \text { (24) }\end{array}$ & $\begin{array}{c}\mathrm{n}=311 \\
\text { Mulheres } \\
25-50 \text { anos } \\
\text { IMC } 27-40 \mathrm{~kg} / \mathrm{m}^{2}\end{array}$ & 12 meses & $\begin{array}{l}\text { Baixo teor de carboidratos: sem } \\
\text { restrição energética; } 50 \text { g de } \\
\text { carboidratos } \\
\text { Ponto Z: sem restrição energética; } \\
40 \% \text { de energia de carboidratos, } \\
30 \% \text { de proteínas e } 30 \% \text { de lipídeos } \\
\text { Prudente (LEARN): restrição } \\
\text { energética; } 55 \%-60 \% \text { de energia de } \\
\text { carboidratos, <10\% de saturados } \\
\text { Baixo teor de lipídeos: sem restrição } \\
\text { energética; < } 10 \% \text { de energia de } \\
\text { lipídeos }\end{array}$ & $\begin{array}{l}\text { Perda de peso significativa } \\
\text { (modesta) e maior na dieta de baixo } \\
\text { teor de carboidratos, sem diferença } \\
\text { entre as outras } 3 \text { dietas: } \\
\text { Baixo teor de carboidratos: } 5,5 \% \\
\text { Ponto Z: } 1,9 \% \\
\text { Prudente: } 3,1 \% \\
\text { Baixo teor de lipídeos: } 2,6 \% \\
\text { * } 0 \text { consumo calórico diário não } \\
\text { diferiu entre os participantes que } \\
\text { seguiram as dietas ao longo do estudo } \\
\text { *Analisados todos os pacientes } \\
\text { randomizados }\end{array}$ & $\begin{array}{l}\text { Baixo teor de carboidratos: } 12 \% \\
\text { Ponto Z: } 23 \% \\
\text { Prudente: } 24 \% \\
\text { Baixo teor de lipídeos: } 22 \% \\
\text { Três recordatórios de } 24 \text { horas } \\
\text { aplicados por telefone no basal, } \\
\text { 2, } 6 \text { e } 12 \text { meses }\end{array}$ \\
\hline $\begin{array}{l}\text { Keogh e cols. } \\
\text { Br J Nutr. } 2007 \\
(25)\end{array}$ & $\begin{array}{c}\quad n=73 \\
\text { Adultos } \\
\text { insulina de jejum } \\
>15 \mathrm{IU} / \mathrm{L} \\
20-65 \text { anos } \\
\text { IMC } 27-40 \mathrm{~kg} / \mathrm{m}^{2}\end{array}$ & 13 meses & $\begin{array}{l}\text { Dietas com } 1.400 \mathrm{kcal} / \mathrm{dia} \text { e } \\
\text { < } 10 \% \text { de saturados: } \\
\text { Rica em monoinsaturados: } 50 \% \text { de } \\
\text { energia de lipídeos, } 30 \% \text { de } \\
\text { carboidratos e } 20 \% \text { de proteínas } \\
\text { Rica em proteínas: } 40 \% \text { de energia } \\
\text { de proteínas, } 30 \% \text { de carboidratos e } \\
30 \% \text { de lipídeos }\end{array}$ & $\begin{array}{l}\text { Perda de peso significativa e sem } \\
\text { diferença entre as dietas: } \\
\text { Rica em monoinsaturados: } \\
8,2 \pm 8,4 \% \\
\text { Rica em proteínas: } 4,8 \pm 6,6 \% \\
\text { * Analisados todos os pacientes } \\
\text { randomizados }\end{array}$ & $\begin{array}{l}\text { Rica em monoinsaturados: 15,8\% } \\
\text { Rica em proteínas: 0\% } \\
\text { Registros alimentares de } 3 \text { dias e } \\
\text { excreção urinária de } 24 \text { horas de } \\
\text { ureia e razão creatinina-ureia a } \\
\text { cada visita }\end{array}$ \\
\hline $\begin{array}{l}\text { Cheskin e cols. } \\
\text { Diabetes Educ. } \\
2008(28)\end{array}$ & $\begin{array}{c}\mathrm{n}=119 \\
\text { DM tipo } 2 \\
53,7 \% \text { mulheres } \\
\text { Idade de } 18-70 \\
\text { anos } \\
\text { IMC } 25-40 \mathrm{~kg} / \mathrm{m}^{2}\end{array}$ & 19 meses & $\begin{array}{l}\text { Dietas com restrição energética de } \\
25 \% \text { das kcal/dia na fase } 1 \\
\text { (emagrecimento) e } 10 \% \text { na fase de } \\
\text { manutenção: } \\
\text { Intervenção: substituiç̃̃es de } \\
50 \%-60 \% \text { das refeições (sem } \\
\text { especificação de qual a refeição ou o } \\
\text { horário) por alimentos com baixo IG e } \\
\text { derivados de soja (barras de cereais, } \\
\text { sopas ou bebidas tipo shakes) } \\
\text { Controle: conforme recomendações } \\
\text { da ADA }\end{array}$ & $\begin{array}{l}\text { Perda de peso significativa e não } \\
\text { diferente entre as dietas: } \\
\text { Intervenção: } 5,5 \% \\
\text { Controle: } 4,7 \% \\
{ }^{*} \text { Analisados somente os pacientes } \\
\text { que completaram o estudo }\end{array}$ & $\begin{array}{l}\text { Intervenção: } 42,6 \% \\
\text { Controle: } 70,7 \% \\
\text { Não há descrição de como foi } \\
\text { avaliada a aderência }\end{array}$ \\
\hline
\end{tabular}


Tabela 4. Ensaios clínicos randomizados que compararam o efeito de diferentes dietas de emagrecimento na perda de peso de indivíduos adultos (2007 a 2009) (continuação)

\begin{tabular}{|c|c|c|c|c|c|}
\hline $\begin{array}{c}\text { Autores } \\
\text { Revista, ano }\end{array}$ & $\begin{array}{c}\text { Amostra em } \\
\text { estudo }\end{array}$ & $\begin{array}{l}\text { Duração } \\
\text { do estudo }\end{array}$ & Dietas propostas & $\begin{array}{c}\text { Redução ponderal } \\
\text { em relação ao } \\
\text { peso inicial }\end{array}$ & $\begin{array}{c}\text { Taxa de abandono } \\
\text { e instrumento(s) de medida } \\
\text { de aderência à dieta }\end{array}$ \\
\hline $\begin{array}{l}\text { Ma e cols. } \\
\text { Nutrition. } 2008 \\
\text { (31) }\end{array}$ & $\begin{array}{c}n=42 \\
\text { DM tipo } 2 \\
(\mathrm{HbA} 1 \mathrm{C}>7,0 \%) \\
53 \% \text { mulheres } \\
53,5 \pm 8,4 \text { anos } \\
\text { IMC médio } \\
35,8 \mathrm{~kg} / \mathrm{m}^{2}\end{array}$ & 12 meses & $\begin{array}{l}\text { Sem informaç̧ão sobre restrição } \\
\text { energética: } \\
\text { Baixo IG: } 55 \% \text { de energia de } \\
\text { carboidratos, preferencialmente } \\
\text { carboidratos de baixo IG (<55\%) } \\
\text { Controle: dieta conforme ADA, com } \\
55 \% \text { de energia de carboidratos, } \\
\text { sem distinção quanto ao tipo } \\
\text { * Alimento referência para cálculo } \\
\text { do IG: pão branco }\end{array}$ & $\begin{array}{l}\text { Perda de peso (desfecho } \\
\text { secundário) significativa e não } \\
\text { diferente entre as dietas: } \\
\text { Baixo IG: } 1,38 \% \\
\text { Controle: } 0,78 \% \\
\text { *Ao longo do estudo o IG entre as dietas } \\
\text { não foi diferente ( } 78 \text { vs. } 81 \%, p=0,07 \text { ) } \\
\text { * Não há descrição se as análises } \\
\text { foram feitas com todos os pacientes } \\
\text { randomizados ou somente os que } \\
\text { completaram o estudo }\end{array}$ & $\begin{array}{l}\text { Não referem se houve perdas de } \\
\text { seguimento } \\
\text { Sete recordatórios diários } \\
\text { aplicados semestralmente }\end{array}$ \\
\hline $\begin{array}{l}\text { Shai e cols. } \\
\text { NEJM. } 2008 \text { (32) }\end{array}$ & $\begin{array}{c}n=322 \\
14 \% \text { mulheres } \\
40-65 \text { anos } \\
\text { IMC }>27 \mathrm{~kg} / \mathrm{m}^{2}\end{array}$ & 24 meses & $\begin{array}{l}\text { Dietas com restrição energética de } \\
300-600 \text { kcal/dia: } \\
\text { Baixo teor de carboidratos: } \\
120 \text { g/dia com ênfase em produtos } \\
\text { proteicos de origem vegetal e } \\
\text { redução no conteúdo de trans } \\
\text { Mediterrânea: } 1.500 \text { kcal mulheres e } \\
1.800 \text { kcal homens, } 35 \% \text { de energia } \\
\text { de lipídeos (óleo de oliva e } \\
\text { oleaginosas) } \\
\text { Prudente: } 1.500 \text { kcal mulheres e } \\
1.800 \text { kcal homens, 30\% de energia } \\
\text { de lipídeos (<10\% de saturados) } \\
\text { * Oferta de refeições (almoço) em cantina } \\
\text { com cardápio direcionado e orientações } \\
\text { espećfícas no cardápio diário }\end{array}$ & $\begin{array}{l}\text { Perda de peso significativa após as } \\
3 \text { dietas foi maior na dieta com } \\
\text { baixo teor de carboidratos e na } \\
\text { mediterrânea: } \\
\text { Baixo teor de carboidratos: } 5,1 \% \\
\text { Mediterrânea: } 4,8 \% \\
\text { Prudente: } 3,2 \% \\
\text { * Analisados todos os pacientes } \\
\text { randomizados }\end{array}$ & $\begin{array}{l}\text { Taxa de abandono de 4,6\% no } \\
\text { primeiro ano e 15,4\% ao final do } \\
\text { segundo ano de seguimento, com } \\
\text { diferença entre os tipos de dieta } \\
\text { ( } p=0,04) \text { : } \\
\text { Baixo teor de carboidratos: } 22 \% \\
\text { Mediterrânea: } 14,7 \% \\
\text { Prudente: } 9,6 \% \\
\text { Questionários de frequência } \\
\text { alimentar eletrônicos autoaplicados } \\
\text { e medida de cetonúria a cada } 6 \\
\text { meses }\end{array}$ \\
\hline $\begin{array}{l}\text { Thorpe e cols. } \\
\text { J Nutrition. } 2008 \\
\text { (33) }\end{array}$ & $\begin{array}{c}n=130 \\
45,4 \% \text { mulheres } \\
30-65 \text { anos } \\
\text { IMC } \geq 26 \mathrm{~kg} / \mathrm{m}^{2}\end{array}$ & 12 meses & $\begin{array}{l}\text { Dietas com } 1.500 \mathrm{kcal} / \mathrm{dia} \text { para } \\
\text { mulheres e } 1.700 \mathrm{kcal} / \text { dia para } \\
\text { homens: } \\
\text { Rica em proteínas: } 30 \% \text { de energia } \\
\text { de proteínas, } 40 \% \text { de carboidratos e } \\
30 \% \text { de lipídeos } \\
\text { Controle (prudente): } 15 \% \text { de } \\
\text { proteínas, } 55 \% \text { de carboidratos e } \\
30 \% \text { de lipídeos }\end{array}$ & $\begin{array}{l}\text { Perda de peso significativa em } \\
\text { ambas as dietas e sem diferença } \\
\text { entre elas: } \\
10,5 \%(8,9-12,0) \\
{ }^{*} \text { Manuscrito não apresenta dados } \\
\text { individuais de perda ponderal de } \\
\text { acordo com a dieta } \\
\text { * Excluídos pacientes outliers nas } \\
\text { análises }\end{array}$ & $\begin{array}{l}\text { Dieta rica em proteínas: } 35,9 \% \\
\text { Dieta controle: } 53,0 \% \\
\text { Três dias de recordatório alimentar } \\
\text { a cada } 4 \text { meses }\end{array}$ \\
\hline $\begin{array}{l}\text { Sacks e cols. } \\
\text { NEJM. } 2009 \text { (35) }\end{array}$ & $\begin{array}{c}n=811 \\
60 \% \text { mulheres } \\
30-70 \text { anos } \\
\text { IMC } \\
25-40 \mathrm{~kg} / \mathrm{m}^{2}\end{array}$ & 12 meses & $\begin{array}{l}\text { Dietas com restrição energética de } \\
750 \mathrm{kcal} / \text { dia, < } 8 \% \text { de saturados e } \\
<150 \mathrm{mg} / 1.000 \text { kcal de colesterol, } \\
\text { com pelo menos } 20 \text { g de fibras ao } \\
\text { dia e recomendação de alimentos } \\
\text { ricos em carboidratos com baixo IG: } \\
\text { Baixo teor lipídeos, moderada em } \\
\text { proteínas: } 20 \% \text { de energia de } \\
\text { lipídeos, } 15 \% \text { de proteínas e } 65 \% \\
\text { de carboidratos } \\
\text { Baixo teor lipídeos, rica em } \\
\text { proteínas: } 20 \% \text { de lipídeos, } 25 \% \text { de } \\
\text { proteínas e } 55 \% \text { de carboidratos } \\
\text { Rica em lipídeos, moderada em } \\
\text { proteínas: } 40 \% \text { de lipídeos, } 15 \% \text { de } \\
\text { proteínas e } 45 \% \text { de carboidratos } \\
\text { Rica em lipídeos, rica em proteínas: } \\
40 \% \text { de lipídeos, } 25 \% \text { de proteínas } \\
\text { e } 35 \% \text { de carboidratos }\end{array}$ & $\begin{array}{l}\text { Perda de peso significativa } \\
\text { (modesta) e não diferente entre as } \\
\text { dietas: } \\
\text { Baixo teor lipídeos, moderada em } \\
\text { proteínas: } 3,1 \% \\
\text { Baixo teor lipídeos, rica em } \\
\text { proteínas: } 3,6 \% \\
\text { Rica em lipídeos, moderada em } \\
\text { proteínas: } 3,6 \% \\
\text { Rica em lipídeos, rica em proteínas: } \\
3,6 \% \\
{ }^{*} \text { Analisados todos os pacientes } \\
\text { randomizados }\end{array}$ & $\begin{array}{l}\text { Baixo teor de lipídeos, moderada } \\
\text { em proteínas: } 17,2 \% \\
\text { Baixo teor de lipídeos, rica em } \\
\text { proteínas: } 22,3 \% \\
\text { Rica em lipídeos, moderada em } \\
\text { proteínas: } 26,0 \% \\
\text { Rica em lipídeos, rica em proteínas: } \\
16,4 \% \\
\text { Recordatórios alimentares de } 5 \\
\text { dias (50\% dos participantes), } 3 \\
\text { dias de recordatórios de } 24 \text { horas } \\
\text { aplicados por telefone, } \\
\text { questionários de saciedade, } \\
\text { comportamento e compulsão } \\
\text { alimentar e satisfação à dieta, além } \\
\text { de medidas de nitrogênio urinário } \\
\text { (24 horas) e coeficiente respiratório } \\
\text { a cada semestre }\end{array}$ \\
\hline
\end{tabular}

DM: diabetes melito; NCEP ATP III: Third Report of the Expert Panel on Detection, Evaluation, and Treatment of High Blood Cholesterol in Adults (Adult Treatment Panel III); TOTG: teste oral de tolerância à glicose (75g); ADA: American Diabetes Association; HbA1C: hemoglobina glicada; IG: índice glicêmico (medida do impacto do carboidrato dos alimentos na glicose plasmática), CG: carga glicêmica (produto entre IG e a quantidade de carboidrato do alimento). 
Os tipos de instrumentos utilizados para avaliação da aderência às dietas foram: recordatórios alimentares de 24 horas aplicados nas consultas ou por telefone ao longo do seguimento do estudo; questionários de frequência alimentar aplicados semestralmente; medidas de gasto energético total através de água duplamente marcada; taxa de metabolismo basal por calorimetria indireta; excreção de ureia, creatinina e cetonas urinárias coletadas a cada visita em intervalos de quatro a seis meses; escalas analógicas para autorrelato de saciedade, fome, satisfação à dieta prescrita; questionários específicos sobre comportamento e compulsão alimentar, além do comparecimento às consultas ou encontros agendados.

\section{Métodos de intervenção dietoterápica}

Em todos os estudos incluídos na presente revisão, as dietas foram orientadas por nutricionistas, utilizandose diversos tipos de materiais (folders, livros, acesso a sites na internet específicos, manuais) para orientação dos participantes quanto à dieta proposta, além de abordagem sobre comportamento alimentar, sugestão de receitas, modo de preparo dos alimentos e lista de alimentos permitidos e restritos. Em 13 estudos foram realizadas atividades de educação nutricional com equipe multidisciplinar. Os encontros, com 10 a 20 participantes, ocorreram com periodicidade variada - sessões semanais ou até bimestrais $(14,19-24,28,31,32,34,35)$ - e foram realizados a intervalos de tempo menores no início das intervenções. Além de esclarecimentos sobre a dieta proposta, foram realizadas abordagens sobre comportamento alimentar (21-24,28,31,32,34,35) baseadas na terapia cognitivo-comportamental (28) e oficinas culinárias $(20,31)$. Somente três estudos forneceram alimentos $(21,30)$ ou refeições aos participantes (32). Em três estudos os participantes receberam incentivos financeiros $(19,22,24)$. Estímulo formal para a prática de atividade física foi descrito em dez estudos (16-18,20,23,24,28,31,34,35).

\section{Perda ponderal}

A perda ponderal obtida nas dietas ao final dos estudos variou de $0,38 \%$ a $10,5 \%$ do peso inicial dos participantes. A perda ponderal de pelo menos $5 \%$ após o seguimento de pelo menos um tipo de dieta proposta foi observada em 17 dos 23 estudos (14,16-25,27-29,32$34)$, sendo 11 desses estudos com restrição energética $(16,17,19-21,25,28,29,32-34)$. Em pacientes obesos, as dietas ricas em ácidos graxos monoinsaturados e com restrição moderada a intensa de carboidratos apresentaram maior perda ponderal nos indivíduos hiperinsulinêmicos (valores de insulina em jejum > $15 \mu \mathrm{IU} / \mathrm{L}$ ) (25). A adoção de dieta ad libitum com baixa CG também apresentou melhor efeito em indivíduos obesos na presença de maior resposta hiperinsulinêmica em teste de tolerância oral à glicose (TOTG; valores de insulina $>150 \mu \mathrm{IU} / \mathrm{L}, 30$ minutos após teste) quando comparada à dieta restrita em lipídeos (22). Em mulheres com excesso de peso e menor escore de sensibilidade à ação da insulina (<6,3 $\mathrm{G} \mathrm{mIU}^{-1} \mathrm{l}^{-1}$ após TOTG), a adoção de dietas com restrição moderada ( $40 \%$ da energia) ou intensa $(<50 \mathrm{~g} /$ dia $)$ de carboidratos promoveu maior perda ponderal do que a dieta controle (18).

\section{Perda ponderal adequada, restrição energética e macronutrientes}

A importância da composição e tipo de macronutrientes e/ou de alimentos específicos na perda de peso em dietas de emagrecimento foi avaliada em dietas com restrição de energia diária e cuja perda ponderal foi considerada adequada: perda ponderal $>5 \%$ $(16,17,19-21,23,28,29,32-34)$. Dos seis estudos $(17,19,21,23,29,34)$ com menor número de pacientes ( $<100$ pacientes), quatro deles $(17,19,21,29$,$) tiveram$ resultados negativos ao comparar dietas com diferentes proporções de macronutrientes $(19,21,29,33)$ ou ao promover o incremento no consumo de fontes alimentares de cálcio, fibras e carboidratos com baixo IG (17). Diferenças significativas entre as dietas foram descritas em apenas dois ECR $(23,34)$. Em um pequeno grupo de mulheres com mais de 65 anos, a adoção de uma dieta prudente com restrição de 500 a $750 \mathrm{kcal} /$ dia promoveu redução de $10 \%$ do peso inicial quando comparada a uma dieta habitual (34). Além disso, o incremento no consumo de frutas e vegetais em uma dieta com baixo teor de lipídeos foi capaz de aumentar de $-7,1$ para $-8,7 \%$ a perda ponderal em 97 mulheres adultas (23).

Ao observar os estudos com grande número de pacientes $(16,20,28,32,33,35)$, embora as dietas não tenham sido as mesmas, na maioria deles $(20,28,33,35)$ não foi encontrada diferença na perda ponderal resultante da modificação na composição das dietas (macronutrientes ou alimentos). Em apenas dois estudos $(16,32)$, a substituição de refeições por sopas/lanche ou a modificação dos componentes da dieta resultou em diferente perda ponderal entre as dietas. A substituição de duas refeições por sopas em uma dieta prudente foi 
capaz de promover maior perda de peso quando comparada à substituição por dois lanches de mesma quantidade energética por porção $(\sim 100 \mathrm{kcal})(16)$. As dietas restritas em carboidratos e do tipo mediterrâneo foram as intervenções com as quais ocorreu maior perda de peso quando comparadas a uma dieta prudente (32).

\section{DISCUSSÃO}

A presente revisão sistemática demonstrou que, em dietas para emagrecimento para adultos, a modificação nos componentes da dieta resultou em discreta perda ponderal, sendo a perda de peso geralmente consequente à restrição energética e não à modificação dos componentes da dieta. Entre as modificações nos componentes da dieta, os resultados mais promissores parecem estar relacionados à restrição de carboidratos e ao seguimento de uma dieta do tipo mediterrânea.

A importância da restrição energética confirma dados já descritos por outros autores (37). Entre os ensaios clínicos incluídos nesta revisão, a perda ponderal de pelo menos $5 \%$ do peso inicial foi obtida nas dietas com algum tipo de restrição no total de energia ingerida ao longo do dia, independentemente da composição de macronutrientes (16,17,19-21,25,28,29,32-34). A escolha do ponto de corte de $5 \%$ para definir perda ponderal adequada foi feita com base na observação de que a diminuição de peso a partir de $5 \%$ do peso inicial já é capaz de reduzir fatores de risco cardiovasculares relacionados à presença de obesidade, tais como hipertensão arterial e diabetes (12).

Em relação às dietas restritas em carboidratos e ricas em proteínas e lipídeos, dois estudos $(24,32)$ reforçaram os achados de uma metanálise de cinco ECR envolvendo 447 indivíduos, publicada em 2006 (37). Nessa metanálise, na qual a maioria dos estudos teve seis meses de duração, também se demonstrou que uma dieta com baixo teor de carboidratos poderia ser uma alternativa à dieta com baixo teor de lipídeos por promover maior perda ponderal e efeitos metabólicos desejáveis.

Recentemente, um estudo (32) demonstrou maior perda ponderal após dois anos de seguimento de dietas restritas em carboidratos ou do tipo mediterrânea com restrição energética quando comparadas a uma dieta prudente também com restrição energética. Nesse estudo, apesar de somente na dieta restrita em carboidratos não ter sido prescrita restrição energética formal, não foram observadas diferenças entre as ingestões diárias de energia relatadas entre os pacientes dos três grupos de dietas.
Essa observação demonstra uma vantagem da dieta pobre em carboidratos em relação às demais, sugerindo que talvez não seja necessária a restrição energética.

Contudo, deve ser lembrado que muitos indivíduos não conseguem seguir uma dieta com restrição de carboidratos, possivelmente pelas preferências alimentares. De fato, já foi demonstrado (12) que a chance de o indivíduo randomizado para uma dieta restrita em carboidratos não completar o estudo foi de $80 \%$ [Razão de Chances (RC) = 1,8 (IC 95\% 1,2-2,6)] quando comparados aos seguidores de uma dieta com baixo teor de lipídeos. O abandono da dieta pobre em carboidratos ocorreu nos primeiros seis meses de seguimento, sendo que em 12 meses essa diferença deixou de ser significativa: RC 1,4 (IC 95\% 0,9-2,3) (12), ou seja, ou o indivíduo adere à dieta ou desiste precocemente dela.

A maioria dos estudos que avaliaram dietas com baixo IG ou CG falhou em mostrar efeitos benéficos dessas dietas na perda de peso em longo prazo $(21,22,26,31)$. Porém, as perdas de seguimento foram elevadas (26), a comparação de dietas que não diferiram apenas no IG, a perda de peso como desfecho secundário (31) e as diferenças na forma de prescrever e nos valores de IG das dietas entre os estudos podem ter contribuído para esses resultados negativos. Apenas um estudo que estratificou os participantes de acordo com o grau de insulinemia demonstrou maior perda de peso pelos pacientes com valores maiores de insulinemia que adotaram a dieta de baixa CG em comparação à dieta com restrição de gordura, sugerindo uma interação entre dieta e fenótipo envolvendo a secreção de insulina (22).

Benefícios cardiovasculares são atribuídos à dieta do tipo mediterrâneo com ingestão moderada de gorduras (rica em ácidos graxos monoinsaturados) $(38,39)$, a qual também é apontada como alternativa para a promoção de perda de peso por ensaio clínico incluído na presente revisão (24) e em revisão sistemática publicada recentemente (40). Entretanto, os estudos reunidos nesta revisão (40) não apresentam resultados uniformes. É importante destacar que o seguimento de uma dieta do tipo mediterrânea pode representar uma prescrição não factível para indivíduos com menor poder aquisitivo ou ainda por diferenças marcadas nos alimentos recomendados em relação aos hábitos alimentares e culturais das populações. Além disso, a influência de outros fatores ambientais, como o nível de atividade física dos indivíduos residentes na região mediterrânea, são aspectos que também devem ser considerados. Na tabela 5 estão descritos os principais componentes da dieta mediterrânea. 
Tabela 5. Componentes alimentares da dieta mediterrânea

\begin{tabular}{lc}
\hline Grupos de alimentos & Quantidade (g ou mL) \\
\hline Vegetais (por dia) & $500-550$ \\
Legumes (por dia) & $5-10$ \\
Frutas, nozes e oleaginosas (por dia) & $350-360$ \\
Queijos e iogurtes (por dia) & $190-200$ \\
Cereais: farinhas, flocos, massas, arroz, outros grãos, pães, cereais matinais, biscoitos e produtos de cereais (por dia) & $140-180$ \\
Carnes (por dia) & $90-120$ \\
Peixes (por semana) & $125-180$ \\
Óleos de oliva (por dia) & $35-45$ \\
Batatas (por dia) & $65-90$ \\
Ovos (por semana) & $100-150$ (2-3 unidades) \\
Vinho tinto durante as refeições (g etanol por dia) & $10-30$ \\
Alimentos açucarados (por dia) & $20-25$
\end{tabular}

Fonte: Adaptado de Trichopoulou e cols. (41).

Na presente revisão, o uso de substituição de refeições como estratégia para perda de peso não foi mais efetivo do que a restrição energética em si $(16,17,19,28)$. Entretanto, um aspecto interessante desse tipo de dieta é que ela poderia estar associada à maior facilidade de seguimento. Em pacientes com DM tipo 2 quando foi realizada a substituição de cerca de metade das refeições por alimentos com baixo IG e derivados de soja, essa dieta teve melhor aderência $(57,4 \%)$ quando comparada à dieta controle $(29,3 \%)$, conforme orientações da American Diabetes Association (40).

A preferência dos pacientes em seguir ou não um tipo de dieta parece ter influência na perda de peso. Dietas vegetarianas parecem promover maior perda ponderal quando comparadas a dietas onívoras (27). Interessantemente, quando os pacientes foram estratificados de acordo com a preferência pelas dietas para as quais eles foram randomizados, a perda de peso foi maior no estrato dos pacientes que não preferiram a dieta para a qual eles foram randomizados (fosse ovolactovegetariana ou controle).

Em dietas para emagrecimento, independentemente do tipo de dieta prescrita, há associação direta entre a aderência à dieta e a perda de peso. Em um dos ECR incluídos na presente revisão (12) foi demonstrada maior perda de peso (cerca de $7 \%$ do peso inicial) diretamente associada aos maiores valores de autorrelato de aderência ao plano alimentar proposto $(r=0,60 ; \mathrm{p}$ $<0,001)$, mas não ao tipo de dieta seguida $(r=0,07$; $\mathrm{p}=0,40)$. Além disso, o acompanhamento continuado e interdisciplinar parece ser um fator importante para a obtenção de perda de peso, conforme descrito em um estudo conduzido com mulheres pós-menopáusicas (27). Nesse estudo, aquelas mulheres que participaram de grupos de apoio perderam mais peso do que aquelas que não participaram dos grupos ao longo de dois anos de seguimento, independentemente do tipo de dieta prescrita (27).

Limitações comuns aos ensaios clínicos de perda de peso incluem falhas na avaliação e manutenção da aderência às dietas propostas e diferenças na intensidade das estratégias adotadas da intervenção. Mais da metade dos estudos incluídos nesta revisão apresentou taxa de abandono (perdas de seguimento) a pelo menos um tipo de dieta igual ou maior a $25 \%$. De fato, as taxas de abandono podem ser menores ( $15 \%)$ em condições diferenciadas como, por exemplo, o fornecimento de refeições em uma mesma área física, no próprio local de trabalho, com cardápio variado e ajustado de acordo com os planos alimentares e com orientações visuais na escolha dos alimentos, além de encontros periódicos com nutricionista específica para cada tipo de dieta (32).

\section{CONCLUSÕES}

O efeito dos componentes (macronutrientes e/ou alimentos) de dietas para emagrecimento na perda de peso corporal em indivíduos adultos não está esclarecido de forma definitiva. É possível que a redução de carboidratos ou a dieta do tipo mediterrâneo possam surtir maior efeito na perda ponderal do que apenas a restrição energética. Entretanto, a restrição energética, independen- 
temente dos componentes da dieta, é ainda a intervenção mais efetiva para perda ponderal. Aspectos como aceitação, motivação, estratégias de acompanhamento, preferências individuais em relação às dietas de emagrecimento, além de características próprias dos pacientes, precisam ser considerados e mais bem estudados.

Declaração: os autores declaram não haver conflitos de interesse científico neste estudo.

\section{REFERÊNCIAS}

1. World Health Organization. Food and Agriculture Organization. Joint WHO/FAO expert consultation. Diet, Nutrition and the Prevention of Chronic Diseases. Geneva:WHO/FAO; 2003.

2. WHO. Obesity and overweight [página na internet]. World Health Organization. 2003. Disponível em: http://www.who.int/hpr/NPH/ docs/gs_obesity.pdf. Acesso em: 3 fev. 2009.

3. Instituto Brasileiro de Geografia e Estatística (IBGE). Pesquisa de Orçamentos Familiares (POF) 2002-2003. Ministério do Planejamento, Orçamento e Gestão, 2006.

4. Ministério da Saúde. PNDS 2006. Pesquisa Nacional de Demografia e Saúde da Criança e da Mulher - Relatório. Brasília/DF, 2008. Disponivel em: http://bvsms.saude.gov.br/bvs/pnds/img/ relatorio_final_pnds2006.pdf. Acesso em: 17 out. 2008.

5. Vedana EH, Peres MA, Neves J, Rocha GC, Longo GZ. Prevalence of obesity and potential causal factors among adults in southern Brazil. Arq Bras Endocrinol Metabol. 2008;52(7):1156-62.

6. Serdula MK, Mokdad AH, Williamson DF, Galuska DA, Mendlein JM, Heath GW. Prevalence of attempting weight loss and strategies for controlling weight. JAMA. 1999;282:1353-8.

7. MaY, Pagoto SL, Griffith JA, Merriam PA, Ockene IS, Hafner AR, et al. A Dietary Quality Comparison of Popular Weight-Loss Plans. J Am Diet Assoc. 2007;107(10):1786-91.

8. Freedman MR, King J, Kennedy E. Popular diets: a scientific review. Obes Res. 2001;9:1S-40S.

9. Kennedy ET, Ohls J, Carlson S, Fleming K. The healthy eating index: design and applications. J Am Diet Assoc. 1995;10:103-8

10. USDA. Center for Nutrition Policy and Promotion. Healthy Eating Index. Disponível na internet via http://www.cnpp.usda.gov/publications/hei/HEl89-90report.pdf. Acesso em: 30 mar. 2009.

11. Foster-Powell K, Holt SHA, Brand-Miller JC. International table of glycemic index and glycemic load values: 2002. Am J Clin Nutr. 2002:76:5-56.

12. Dansinger ML, Gleason JA, Griffith JL, Selker HP, Schaefer EJ. Comparison of the Atkins, Ornish, weight watchers, and zone diets for weight loss and heart disease risk reduction: a randomized trial. JAMA. 2005;293:43-53.

13. Franz MJ, Van Wormer JJ, Crain AL, Boucher JL, Histon T, Caplan $\mathrm{W}$, et al. Weight-loss outcomes: a systematic review and metaanalysis of weight-loss clinical trials with a minimum 1-year follow-up. J Am Diet Assoc. 2007;107(10):1755-67.

14. Due A, Toubro S, Skov AR, Astrup A. Effect of normal-fat diets, either medium or high in protein, on body weight in overweight subjects: a randomized 1-year trial. Int J Obes. 2004;28:1283-90.

15. Li Z, Hong K, Saltsman P, DeShields S, Bellman M, Thames G, et al. Long-term efficacy of soy-based meal replacements vs an individualized diet plan in obese type II DM patients: relative effects on weight loss, metabolic parameters, and C-reactive protein. Eur J Clin Nutr. 2005;59(3):411-8.
16. Rolls BJ, Roe LS, Beach AM, Kris-Etherton PM. Provision of foods differing in energy density affects long-term weight loss. Obesity Research. 2005;13(6):1052-60.

17. Thompson WG, Rostad Holdman N, Janzow DJ, Slezak JM, Morris $\mathrm{KL}$, Zemel MB. Effect of energy-reduced diets high in dairy products and fiber on weight loss in obese adults. Obes Res. 2005:13(8):1344-53

18. McAuley KA, Smith KJ, Taylor RW, McLay RT, Williams SM, Mann $\mathrm{JI}$. Long-term effects of popular dietary approaches on weight loss and features of insulin resistance. Int J Obes. 2006;30(2):342-9.

19. Ashley JM, Herzog H, Clodfelter S, Bovee V, Schrage J, Pritsos C. Nutrient adequacy during weight loss interventions: a randomized study in women comparing the dietary intake in a meal replacement group with a traditional food group. Nutr J. 2007;6:12.

20. Burke LE, Hudson AG, Warziski MT, Styn MA, Music E, Elci OU, et al. Effects of a vegetarian diet and treatment preference on biochemical and dietary variables in overweight and obese adults: a randomized clinical trial. Am J Clin Nutr. 2007;86(3):588-96.

21. Das SK, Gilhooly CH, Golden JK, Pittas AG, Fuss PJ, Cheatham $\mathrm{RA}$, et al. Long-term effects of 2 energy-restricted diets differing in glycemic load on dietary adherence, body composition, and metabolism in CALERIE: a 1-y randomized controlled trial. Am J Clin Nutr. 2007;85(4):1023-30.

22. Ebbeling CB, Leidig MM, Feldman HA, Lovesky MM, Ludwig DS. Effects of a low-glycemic load vs low-fat diet in obese young adults: a randomized trial. JAMA. 2007;297(19):2092-102.

23. Ello-Martin JA, Roe LS, Ledikwe JH, Beach AM, Rolls BJ. Dietary energy density in the treatment of obesity: a year-long trial comparing 2 weight-loss diets. Am J Clin Nutr. 2007;85(6):1465-77.

24. Gardner CD, Kiazand A, Alhassan S, Kim S, Stafford RS, Balise RR, et al. Comparison of the Atkins, Zone, Ornish, and learn diets for change in weight and related risk factors among overweight premenopausal women: the $A$ to $Z$ weight loss study: a randomized trial. JAMA. 2007;297(9):969-77.

25. Keogh JB, Luscombe-Marsh ND, Noakes M, Wittert GA, Clifton $\mathrm{PM}$. Long-term weight maintenance and cardiovascular risk factors are not different following weight loss on carbohydrate-restricted diets high in either monounsaturated fat or protein in obese hyperinsulinaemic men and women. $\mathrm{Br} \mathrm{J}$ Nutr. 2007;97(2):405-10.

26. Sichieri R, Moura AS, Genelhu V, Hu F, Willett WC. An 18-mo randomized trial of a low-glycemic-index diet and weight change in Brazilian women. Am J Clin Nutr. 2007;86(3):707-13.

27. Turner-McGrievy GM, Barnard ND, Scialli AR. A two-year randomized weight loss trial comparing a vegan diet to a more moderate low-fat diet. Obesity (Silver Spring). 2007;15(9):2276-81.

28. Cheskin LJ, Mitchell AM, Jhaveri AD, Mitola AH, Davis LM, Lewis RA, et al. Efficacy of meal replacements versus a standard foodbased diet for weight loss in type 2 diabetes: a controlled clinical trial. Diabetes Educ. 2008;34(1):118-27.

29. Clifton PM, Keogh JB, Noakes M. Long-term effects of a highprotein weight-loss diet. Am J Clin Nutr. 2008;87(1):23-9.

30. Kawashima $H$, Takase $H$, Yasunaga $K$, Wakaki $Y$, Katsuragi $Y$, Mori $\mathrm{K}$, et al. One-year ad libitum consumption of diacylglycerol oil as part of a regular diet results in modest weight loss in comparison with consumption of a triacylglycerol control oil in overweight Japanese subjects. J Am Diet Assoc. 2008;108(1):57-66.

31. Ma Y, Olendzki BC, Merriam PA, Chiriboga DE, Culver AL, Li W, et al. A randomized clinical trial comparing low-glycemic index versus ADA dietary education among individuals with type 2 diabetes. Nutrition. 2008;24(1):45-56.

32. Shai I, Schwarzfuchs D, Henkin Y, Shahar DR, Witkow S, Greenberg I, et al. Weight loss with a low-carbohydrate, Mediterranean, or low-fat diet. N Engl J Med. 2008;359(3):229-41. 
33. Thorpe MP, Jacobson EH, Layman DK, He X, Kris-Etherton PM, Evans EM. A diet high in protein, dairy, and calcium attenuates bone loss over twelve months of weight loss and maintenance relative to a conventional high-carbohydrate diet in adults. $J$ Nutr. 2008;138(6):1096-100.

34. Villareal DT, Shah K, Banks MR, Sinacore DR, Klein S. Effect of weight loss and exercise therapy on bone metabolism and mass in obese older adults: a one-year randomized controlled trial. J Clin Endocrinol Metab. 2008;93(6):2181-7.

35. Sacks FM, Bray GA, Carey VJ, Smith SR, Ryan DH, Anton SD, et al. Comparison of weight-loss diets with different compositions of fat, protein, and carbohydrates. N Engl J Med. 2009;360(9):859-73.

36. Journal Citation Reports. Disponível em: http://admin-apps.isiknowledge.com/JCR/JCR. Acesso em: 12 mar. 2009.

37. Nordmann AJ, Nordmann A, Briel M, Keller U, Yancy WS, Brehm $B J$, et al. Effects of low-carbohydrate vs low-fat diets on weight loss and cardiovascular risk factors: a meta-analysis of randomized controlled trials. Arch Intern Med. 2006;166:285-293.

38. Sánchez-Taínta A, Estruch R, Bulló M, Corella D, Gómez-Gracia E, Fiol M, et al. Adherence to a Mediterranean-type diet and reduced prevalence of clustered cardiovascular risk factors in a cohort of 3,204 high-risk patients. Eur J Cardiovasc Prev Rehabil. 2008;15(5):589-93.

39. Sofi F, Cesari F, Abbate R, Gensini GF, Casini A. Adherence to Mediterranean diet and health status: meta-analysis. BMJ. 2008;11:337-44.

40. Buckland G, Bach A, Serra-Majem L. Obesity and the Mediterranean diet: a systematic review of observational and intervention studies. Obes Rev. 2008;9(6):582-93.

41. Trichopoulou A, Costacou T, Bamia C, Trichopoulos D. Adherence to a Mediterranean diet and survival in a greek population. N Engl J Med. 2003;348(26):2599-608. 